\title{
Arbitration Systems and Negotiations
}

\author{
Mercedes Adamuz and Clara Ponsatí*
}

December 2003

\begin{abstract}
We consider a model of bargaining by concessions where agents can terminate negotiations by accepting the settlement of an arbitrator. The impact of pragmatic arbitrators -that enforce concessions that precede their appointment - is compared with that of arbitrators that act on principle - ignoring prior concessions. We show that while the impact of arbitration always depends on how costly that intervention is relative to direct negotiation, the range of scenarios for which it has an impact, and the precise effect of such impact, does change depending on the behavior -pragmatic or on principle- of the arbitrator. Moreover the requirement of mutual consent matters only when the arbitrator is pragmatic.

Efficiency and equilibrium are not aligned since agents sometimes reach negotiated agreements when an arbitrated settlement is more efficient and vice-versa. The second type of inefficiency is avoided when arbitrators are appointed by mutual consent and act pragmatically. What system of arbitration has the best ex-ante performance depends on the distributions of arbitration and negotiation costs, and each can be the second best optimal for plausible environments.

keywords: arbitration, bargaining, concessions, negotiations.
\end{abstract}

*Adamuz is at Departamento de Administración at Instituto Tecnológico Autónomo de México (adamuz@itam.mx) and Ponsatí is at Institut d'Anàlisi Economica-CSIC and CODE-Universitat Autònoma de Barcelona (clara.ponsati@uab.es). 


\section{Introduction}

Arbitration is an extended procedure of dispute resolution by which confronted parties submit to the decision of a third party. It is widely used in divorce proceedings, to settle grievances in union-management contracts, for the dissolution of partnerships, and in international trade. The use of arbitration when direct negotiation fails is often included as a clause in contracts and sometimes it is imposed by law.

To address the effect of arbitration over negotiations, bargaining games in the shadow of arbitration must be explored. While the literature on arbitration - both empirical and theoretical - is substantial ${ }^{1}$, most models in this literature do not contemplate arbitration and bargaining as alternatives that agents chose along a negotiation process. The notable exceptions are Compte and Jehiel (1995, 2002) and Manzini and Mariotti (2001).

Arbitration may be viewed as an outside option that bargainers have along the negotiation process. The literature on bargaining with outside options $^{2}$ explores the outcomes of non-cooperative bargaining games when agents can exit the negotiation and obtain an external payoff. In this literature, the decision to exit the negotiation can be taken unilaterally by the bargainers and it yields payoffs that are independent of the actions taken during the negotiation process. To think about arbitration, both assumptions may have drawbacks. It is thus important to clarify their distinct implications, and to study models in which they are relaxed.

The assumption that parties can unilaterally exit the negotiation and impose the use of arbitration is justified only in environments where, prior to beginning negotiations, parties commit to allow each other this possibility. Unilateral exit is thus a reasonable assumption to model bargaining under compulsory arbitration - a fairly common institutional arrangement for industrial relations in the U.S. In other cases, however, parties negotiate without this prior commitment, and the decision to call an arbitrator requires mutual consent. ${ }^{3}$ Manzini and Mariotti (2001) sharply make the point that the voluntary nature of arbitration is of great consequence. They propose a

\footnotetext{
${ }^{1}$ See Farber, H. S and M. H. Bazerman (1986), Gibbons (1988) and Kalai, E. and R. Rosenthal (1979).

${ }^{2}$ See Shaked and Sutton (1984), Shaked(1994) and Ponsati and Sakovics (1998).

${ }^{3}$ In Spain and the U.K, for example, labour conflicts are resolved by an arbitrator only with the consent of both parties. See Manzini and Mariotti (2001) for a thorough discussion.
} 
model of bargaining à la Rubinstein where the decision to call an arbitrator is a joint outside option ${ }^{4}$ that both agents must agree to take, showing that outcomes are dramatically different from those of games where outside options are unilateral. The settlements imposed by their arbitrators, however, are independent of the negotiation history.

The assumption that arbitration outcomes are history independent must also be scrutinized. While some arbitrators do act on principle - imposing a fair settlement, independently of the concessions that precede their appointment - there is strong empirical evidence that this is not usually the case. ${ }^{5}$ More often than not, arbitrators do pay attention to the events that precede their appointment, and act pragmatically imposing state dependent settlements that maintain previous concessions. Compte and Jehiel (2002) discuss concession bargaining games where players can unilaterally impose an arbitrated agreement at which payoffs depend on the concessions accumulated prior to exit. They show that endogenous outside options of this kind promote gradualism in the process of concessions, and thus delay and inefficiency. ${ }^{6}$

This paper explores concession bargaining games with different systems of arbitration in the background. We consider two agents that take turns at offering each other concessions, that cannot be claimed back. Negotiations are costly because each round of concessions takes time and players are impatient. When this game is played without an arbitrator in the background, the outcome is ineffcient, agents agree at the Rubinstein shares with one period of delay. ${ }^{7}$ When an arbitrator is present, the negotiation process can be terminated at any point by appointment of the arbitrator. Arbitration is costly as well, either directly, because a payment to the arbitrator consumes a portion of the surplus, or indirectly in terms of delay or other implementation frictions.

There are two rules to appoint the arbitrator, and two norms of conduct

\footnotetext{
${ }^{4}$ See Manzini and Mariotti (2002) for a general disccussion not specifically focussed to arbitration.

${ }^{5}$ Ashenfelter and Bloom (1984), Bloom (1986), Farber and Bazerman, (1986).

${ }^{6}$ The main message of Compte and Jehiel (2002) is general and important for many other applications, since their results apply to a very general class of games admitting several specifications and interpretations. Their previous unpublished work, Compte and Jehiel (1995), presents a discussion focussed to arbitration.

${ }^{7}$ This is in common with Admati and Perry (1991) and Compte and Jeihel (2002). See the latter for a convincing argument that this is an appropriate assumption to model negotiations with arbitration in the background.
} 
by the arbitrator:

1. a) Under unilateral arbitration, players do not need their opponent's approval to bring in the arbitrator; b) under consensus arbitration they do.

2. a) Pragmatic arbitrators, enforce concessions that take place prior to their appointment and split the contested $\left.\operatorname{surplus}^{8} ; \mathrm{b}\right)$ arbitrators that act on principle impose a fair settlement regardless of prior concessions.

Each combination - unilateral pragmatic arbitration, pragmatic arbitration by consensus, unilateral arbitration on principle and arbitration on principle by consensus - constitutes an arbitration system. For each, we characterize the unique (subgame perfect) equilibrium of the corresponding bargaining game for all combinations of negotiation and arbitration costs. We show that while the impact of arbitration always depends on its cost relative to the cost of direct negotiations, the range of scenarios for which it has an impact and the precise effect of such impact changes drastically depending on whether the arbitrator acts on principle or pragmatically. Moreover, for pragmatic arbitrators the requirement of consensus also matters.

When arbitrators are pragmatic, there are three possible equilibrium outcomes: If the cost of arbitration is high, agents ignore arbitration and reach agreement as they would in the game without arbitrator. At the other extreme, if the cost of arbitration is low, then the arbitrator is appointed at the beginning of the game. In between there is a range of moderate costs where arbitration is not used, but it does have impact in the negotiated outcome; negotiated shares - no longer the Rubinstein shares - approach the potential arbitrated settlement. The scenarios at which each of these three outcomes prevail depend on whether arbitration is unilateral or by consensus. In contrast, when arbitrators act on principle they do not have an impact on negotiated agreements: either they are appointed immediately or they are irrelevant. Furthermore, the outcome that prevails is independent of the requirement of mutual consent. ${ }^{9}$

\footnotetext{
${ }^{8}$ This is a reduced form for Conventional Arbitration, where arbitrators tend to compromise between the positions of the two parties. Equal shares of the contested surplus might also be the expected outcome of Final Offer Arbitration - where the arbitrator is constrained to choose one of the final two offers.

${ }^{9}$ This result depends crucially on the concession nature of the bargaining game. As
} 
We show that efficiency and equilibrium outcomes are not aligned. There are scenarios where a negotiated outcome is the more efficient and players appoint the arbitrator, and scenarios where arbitration is efficient and yet, in equilibrium, players negotiate an agreement. Both types of inefficiency may arise when the arbitrator acts on principle or when, being pragmatic, she can be appointed unilaterally. When pragmatic arbitrators are appointed by consensus the first type of efficiency failure is avoided altogether, but the second arises in a greater set of scenarios. Hence, whether one type of arbitrator or another is a priori more effective in promoting efficiency depends on the expected distribution of arbitration and negotiation costs and, except in pathological environments, none of the three arbitration systems can be dismissed as generally dominated by the others. For each system of arbitration we display natural distributions of costs at which it is second best optimal.

The remainder of the paper is organized as follows. Section 2 presents the model. The unique equilibrium when arbitrators are pragmatic is discussed in sections 3 and 4, that address, respectively, unilateral appointment and consensus. Section 5 considers arbitrators that act on principle. Section 6 compares the relative performance of the different systems. Conclusions are gathered in section 6 .

\section{The model}

Two players, $i=1,2$, bargain to share one unit of surplus. Negotiations take place over time and players are risk neutral and impatient. The different games that we consider combine general negotiation rules with a specification of the arbitration system. Negotiation rules, arbitration systems, outcomes and payoffs are described next.

1. The negotiation Rules: Each period $t=0,1,2 \ldots$ players may offer each other, in alternating order with player 1 moving first, mutual concessions; or they may appoint the arbitrator. Thus, at each $t$, and given the bargaining state $\left(x_{1}, x_{2}, X\right), 0 \leq x_{i} \leq 1,0 \leq x_{1}+x_{2} \leq 1$, $X=1-x_{1}+x_{2}$ indicating the cumulative concession to each player in

\footnotetext{
Manzini and Mariotti (2001) show, when agents are not constrained to maintain their concessions, an arbitrator appointed by consent that acts on principle may have great impact.
} 
periods 0 to $t-1$ and the contested surplus, player $i$ must either offer to concede a non-negative additional portion of the surplus $C_{i} \in[0, X]$, or she can move to appoint the arbitrator.

2. ARBitRATION SYSTEMS: An arbitration system specifies the appointment rule and the conduct of the arbitrator. There are two rules of appointment: in unilateral arbitration the game ends when a player moves to appoint the arbitrator; under consensus arbitration, after $i$ moves to appoint the arbitrator, $j$ must accept or reject. The arbitrator conduct specifies a partition of the surplus, $\left(A_{1}, A_{2}\right), A_{i} \geq 0, A_{1}+A_{2}=1$. A pragmatic arbitrator appointed in state $\left(x_{1}, x_{2}, X\right)$ respects concessions and splits the remaining surplus, thus $A_{i}=x_{i}+\frac{X}{2}$. When the conduct of the arbitrator is on principle $A_{i}=\frac{1}{2}$.

3. Outcomes And Payoffs: The game terminates when a player concedes all the contested surplus or the arbitrator is appointed. Otherwise after $i$ moves first at $t$ the game continues with $j$ moving first at $t+1$. Perpetual disagreement yields a zero payoff to both players. Under a negotiated agreement $(x, 1-x, t)$ each player enjoys the accumulated concessions at the date of agreement, i.e. payoffs are $\left(\delta^{t} x, \delta^{t}(1-x)\right)$, where $0<\delta<1$. Upon appointment of the arbitrator in period $t$ at state $\left(x_{1}, x_{2}, X\right)$, the arbitrator prescribes a split of the surplus into shares $\left(A_{1}, A_{2}\right)$, and the cost of arbitration is incurred. Hence, payoffs upon an arbitrated termination are

$$
\left(\delta^{t} \alpha A_{1}, \delta^{t} \alpha A_{2}\right)
$$

where $0<\alpha<1$. A straight forward interpretation is that the arbitrator charges a direct fee proportional to the total surplus. ${ }^{10}$ Even if the arbitrator does not charge a fee, arbitration will still be costly as long as it consumes resources or time. ${ }^{11}$

The extensive forms are displayed Figures 1 and 2.

\footnotetext{
${ }^{10}$ Hence, individual costs of arbitration are proportional to the total share that each agent obtains. This is unlike in Compte and Jehiel (1995).

${ }^{11}$ In this later case, we treat the costs of arbitration as delay costs. That is, while $1-\delta$, $\delta=\exp (-r)$, measures the cost imposed by a one period of delay in the negotiations, a share of the surplus obtained under an arbitrated outcome has a cost $1-\alpha, \alpha=\exp (-r h)$, where $h$ is the real time interval of delay imposed by the arbitrator. Note that $\alpha \leqslant \delta$ if and only if $h \geqslant 1$, i.e. if and only if arbitration takes longer than one round of bargaining.
} 


\section{Unilateral Arbitration}

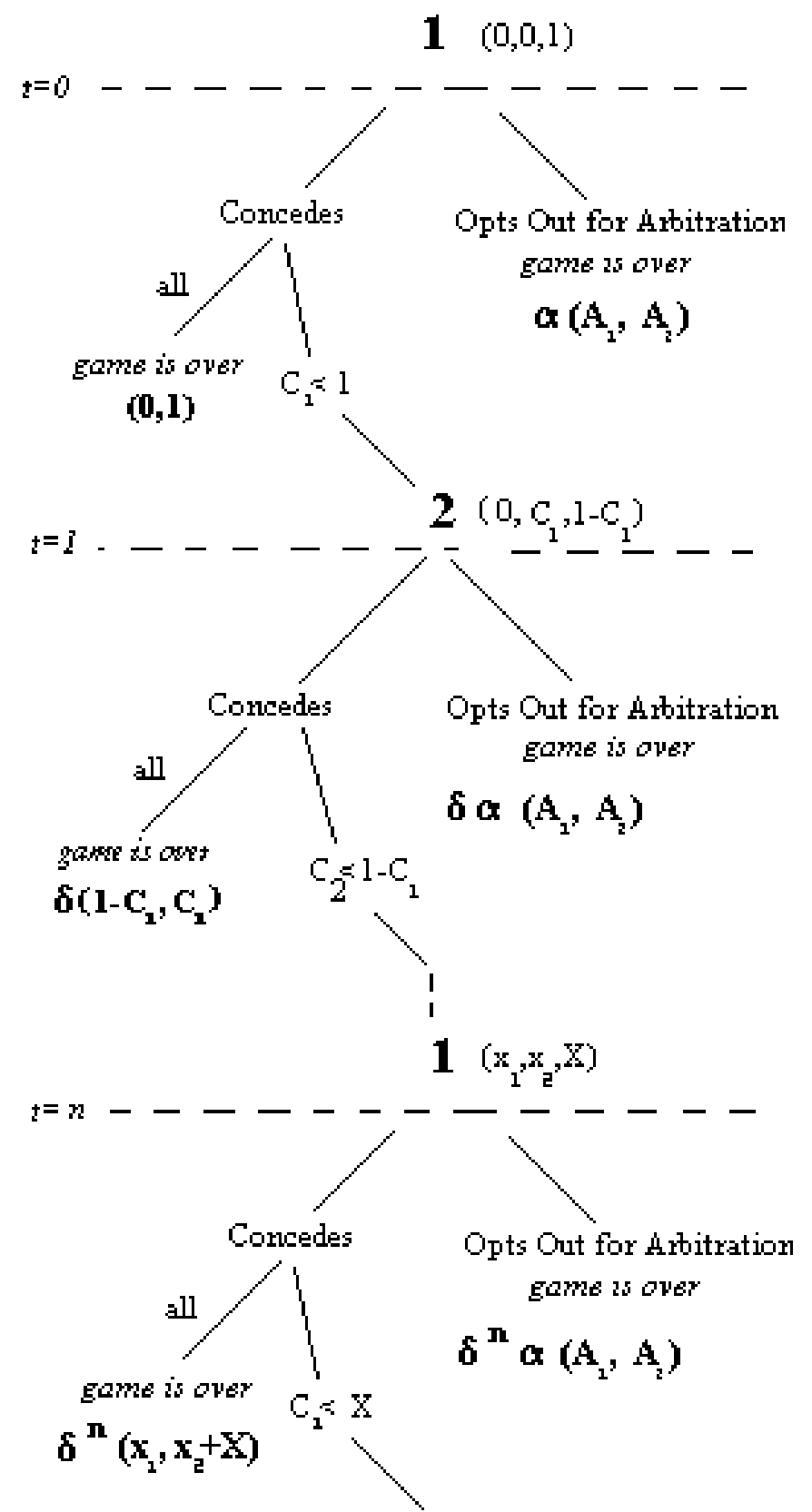

Figure 1 


\section{Consensus Arbitration}

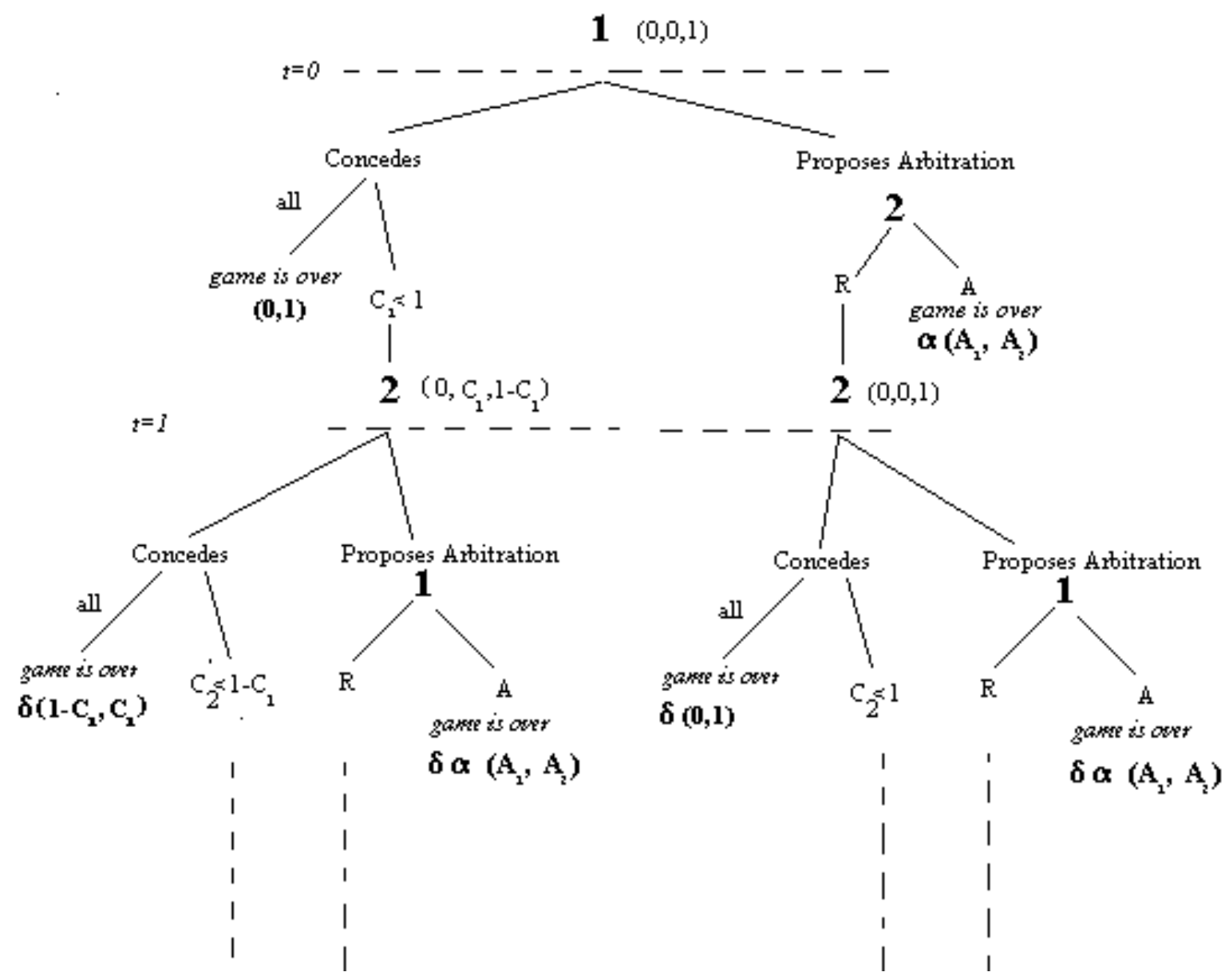

Figure 2

The present games are infinite horizon bargaining games of complete information. In spite of their close relationship to the standard bargaining games of alternating proposals, there are important differences that it is worthwhile to clarify. A first and fundamental difference is that players cannot claim back what they concede. Consequently, after each positive concession, the set of continuation strategies available to the players changes because the possible partitions of the surplus becomes smaller. Moreover, since strategy 
profiles where the first mover concedes the whole surplus can easily be ruled out as equilibria, negotiated agreements take at least one period. Finally, observe that proposing to appoint a pragmatic arbitrator is never equivalent to a concession $C_{i}=\frac{X}{2}$. Appointing the arbitrator terminates de game, and the costs of arbitration are incurred, while a partial concession $\frac{X}{2}$ leads to continuation game at $t+1$ where the contested surplus is $1-x_{1}-x_{2}-\frac{X}{2}$. If the appointment rule requires consensus, moreover, the opponent's rejection of arbitration prompts a continuation game at $t+1$ leaving the bargaining state unchanged.

Strategies specify actions at each subgame (a concession or the move to appoint the arbitrator; and, under consensus, thresholds to approve arbitration), and the set of available actions is constrained by the state of the game. An equilibrium will be a profile of strategies that constitute a subgame perfect equilibrium.

In general, strategies may be extremely complex since actions at any subgame may depend arbitrarily on the entire history of actions up to that point, and the set of histories is large. However the bargaining state summarizes all information of a history that is payoff relevant to a player's choice, and it will turn out that for each state $\left(x_{1}, x_{2}, X\right)$ a unique optimal action can be identified by sequential elimination of dominated actions.

Before we proceed to characterize equilibria in bargaining under arbitration it is useful to discuss the concession game in the absence of arbitration. Without arbitration, only one player moves at each round and she can either concede the rest of the pie, $X$, or make a partial concession $C_{i} \in[0, X]$. This game is discussed by Admati and Perry (1991), its unique equilibrium outcome yields agreement at the standard Rubinstein partition, attained with one period of delay.

Proposition 1 No Arbitration (Admati and Perry): In the absence of arbitration, in equilibrium, player 1 concedes $\frac{\delta}{1+\delta}$ and player 2 concedes the rest, $\frac{1}{1+\delta}$, in the following period.

Proof. See Admati and Perry (1991), Proposition 5.1.

Without arbitration players concede up to the point where the opponent, given that she is impatient, is willing to terminate the game by conceding what is left. Since payoffs are only realized upon agreement, players do not benefit from the concessions they receive until the game ends. Therefore a player that has been granted a concession becomes effectively more impatient, 
delay is more costly for her that than for an opponent that has still nothing assured. If the first concession is large enough the optimal response is to terminate by conceding the rest of the pie. The minimal concession assures such response is the responder's share of the Rubinstein partition.

We now turn our attention to the effect that arbitration has in the preceding concession game. We start by analyzing a game under pragmatic arbitrators, that impose state dependent settlements, under the assumption that they can be appointed unilaterally.

\section{Unilateral Pragmatic Arbitration}

When agents can appoint the arbitrator unilaterally, arbitration is an outside option. Consequently, analyzing the equilibrium behavior of players under unilateral arbitration parallels the analysis of a bargaining game with outside options. The crucial insight is that outside options are not always relevant, and this is likewise with arbitration. Moreover, when the outside option is of endogenous value, varying at the different states of bargaining, its relevance is more delicate than that of fixed outside options.

Pragmatic arbitrators pay some attention to the history of negotiation that proceeds their appointment and prescribe settlements that are state dependent. Thus arbitration is indeed an option of endogenous value. Precisely, this endogenous value is

$$
\alpha A_{i}\left(x_{1}, x_{2}, X\right)=\alpha\left(x_{i}+\frac{X}{2}\right) ;
$$

that is, the accumulated concessions received prior to arbitration are enforced while the contested surplus is split equally, and the cost of arbitration is incurred.

At any subgame only one agent moves, and so she controls the rate at which payoffs are discounted. If she concedes, payoffs are discounted by $\delta$; if the arbitrator is appointed, payoffs are discounted by $\alpha$.

To describe equilibrium profiles we will simply specify the optimal action at each bargaining state. This characterization is given in Lemmata 2 to 5 that examine, in turn, all the state configurations that might arise along play of the game. The detailed proofs are relegated to the appendix. They involve tedious but otherwise straightforward sequential deletion of dominated ac- 
tions, showing that for each state under consideration, the appropriate action survives uniquely.

The following notation simplifies the exposition. Given a state $\left(x_{1}, x_{2}, X\right)$ we denote as $C_{i}^{N}$ the concession of Player $i$ that gives Player $j$ an accumulated concession equivalent to the first mover payoff in the game without arbitration, that is,

$$
C_{i}^{N}+x_{j}=\frac{\delta}{1+\delta}
$$

Similarly, we denote as $C_{i}^{A}$ the concession of Player $i$ that gives Player $j$ an accumulated concession at which she is indifferent between terminating the game with total concession or with arbitration, that is,

$$
C_{i}^{A}+x_{j}=\alpha\left(x_{j}+\frac{X+C_{i}^{A}}{2}\right) .
$$

We start by examining the optimal action at states where the active player has received accumulated concessions that exceed the present value of obtaining all remaining surplus in one period of delay. If the cost of arbitration is sufficiently high, she terminates the game by a total concession; otherwise the arbitrator is appointed.

Lemma 2 In states where $x_{1} \geq \delta\left(x_{1}+X\right)$ the optimal actions of Player 1 are:

1. If $\alpha \leq \frac{2 \delta}{\delta+1}$ concede $X$.

2. If $\alpha>\frac{2 \delta}{\delta+1}$ opt out in states where $\alpha\left(x_{1}+\frac{X}{2}\right)>x_{1}$; otherwise concede $X$.

Let us now examine the optimal actions when the active player faces an opponent that, upon continuation, will be in the situation of Lemma 2.

Lemma 3 In states where $x_{1}<\delta\left(x_{1}+X\right)$ and $x_{2} \geq \delta\left(x_{2}+X\right)$ the optimal actions of Player 1 are:

1. If $\alpha \leq \frac{2 \delta}{\delta+1}$ not to concede anything.

2. If $\alpha>\frac{2 \delta}{\delta+1}$ a concession $C_{1}^{A}$ in states where $\delta\left(x_{1}+X-C_{1}^{A}\right) \geq \alpha\left(x_{1}+\frac{X}{2}\right)$; otherwise to impose arbitration. 
Our next result addresses optimal actions at states where no agent has reached the situation of Lemma 2, but one of the two players has received concessions that exceed $\frac{\delta}{1+\delta}$, that is, the payoff that the first mover attains in the absence of arbitration.

Lemma 4 In states where $x_{i}<\delta\left(x_{i}+X\right), i=1,2$, and either $x_{1} \geq \frac{\delta}{1+\delta}$ or $x_{2} \geq \frac{\delta}{1+\delta}$ the optimal actions of Player 1 are:

1. When $x_{1} \geq \frac{\delta}{1+\delta}$ : i) If $\alpha \leq \frac{2 \delta}{2 \delta+1}$ a concession $X$. ii) If $\frac{2 \delta}{2 \delta+1}<\alpha \leq \frac{2 \delta}{\delta+1}$ a concession $X$ if $x_{1} \geq \alpha\left(x_{1}+\frac{X}{2}\right)$; otherwise to impose arbitration. iii) If $\alpha>\frac{2 \delta}{\delta+1}$ a concession $C_{1}^{A}$ if $\delta\left(x_{1}+X-C_{1}^{A}\right) \geq \alpha\left(x_{1}+\frac{X}{2}\right)$; otherwise to impose arbitration.

2. When $x_{2} \geq \frac{\delta}{1+\delta}:$ No concession if $\alpha \leq \frac{2 \delta}{1+2 \delta}$. Otherwise a concession $C_{1}^{A}$ if $\delta\left(x_{1}+X-C_{1}^{A}\right) \geq \alpha\left(x_{1}+\frac{X}{2}\right)$ and else to impose arbitration.

Considering states where no agent has yet reached accumulated concessions beyond the first mover's payoff in the absence of arbitration completes the exploration of optimal actions.

Lemma 5 In states such that $x_{i}<\frac{\delta}{1+\delta} i=1,2$ the optimal actions of Player 1 are:

1. If $\alpha \leq \frac{2 \delta}{2 \delta+1}$ a concession $C_{1}^{N}$.

2. If $\alpha>\frac{2 \delta}{2 \delta+1}$ a concession $C_{1}=\operatorname{Max}\left[C_{1}^{N}, C_{1}^{A}\right]$ whenever $\delta\left(x_{1}+X-\right.$ $\left.C_{1}\right) \geq \alpha\left(x_{1}+\frac{X}{2}\right)$; or else to impose arbitration.

With a full characterization of the optimal action at each possible bargaining state the full characterization of the equilibrium outcomes is straightforward. It suffices to observe that the optimal actions at the initial state $(0,0,1)$ are given in Lemma 5 . They must necessarily yield either an arbitrated termination or a negotiated agreement that occurs in two steps of concession.

For each state that satisfies the conditions of Lemma 5, the different optimal action scenarios generate a partition in the set of parameters. For the initial state $(0,0,1)$, it is immediate to check that the induced partition 
is as follows. The parameters $(\alpha, \delta)$ for which $C_{i}^{N}=\frac{\delta}{1+\delta}$ is the optimal action must lie in the set

$$
H=\left\{(\alpha, \delta) \text { such that } \alpha \leq \frac{2 \delta}{1+2 \delta}\right\} ;
$$

and the optimal action is $C_{i}^{A}=\frac{\alpha}{2-\alpha}$ at set of parameters

$$
M=\left\{(\alpha, \delta) \text { such that } \frac{2 \delta}{1+2 \delta} \leqslant \alpha<1+2 \delta-\sqrt{1+4 \delta^{2}}\right\} .
$$

The arbitrator is appointed if costs are low, i.e. $(\alpha, \delta) \notin H \cup M$. Figure 3 displays the partition of the set of parameters into scenarios of high, moderate and low costs of arbitration.

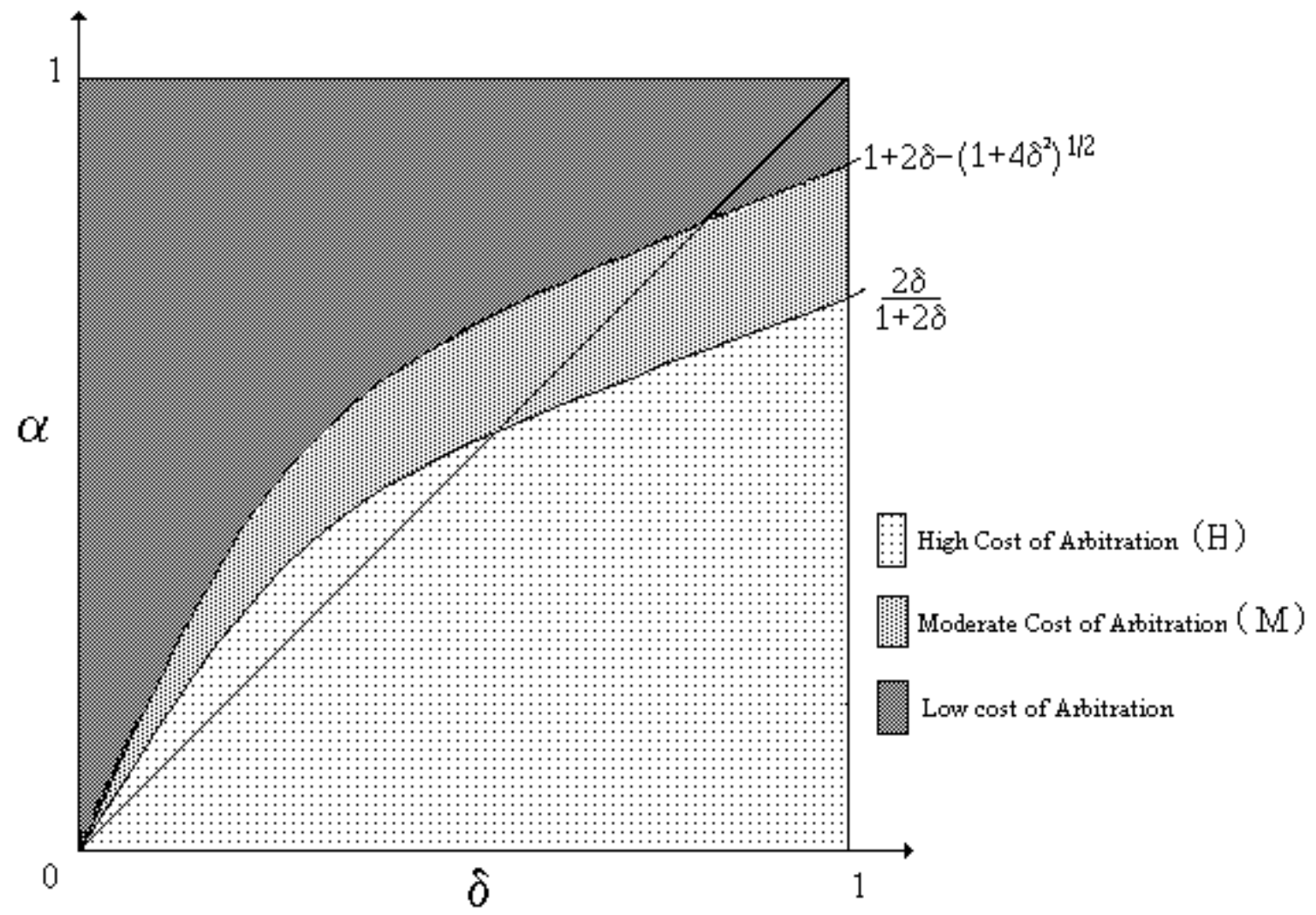

Figure 3 
The main result of this section, characterizing the unique equilibrium outcome for all possible parameters $\alpha$ and $\delta$, is now immediate from Lemma 5 and Lemma 4.

Proposition 6 unilateral PRAGmatic ARBitration: When a pragmatic arbitrator - allocating shares $A_{i}\left(x_{1}, x_{2}, X\right)=x_{i}+\frac{X}{2}$ - can be appointed unilaterally, there is a unique equilibrium. Arbitration prevails if and only if it has low cost, $(\alpha, \delta) \notin H \cup M$, and this outcome occurs at $t=0$. Otherwise a negotiated agreement is reached at $t=1$. The negotiated partition $\left(\frac{1}{1+\delta}, \frac{\delta}{1+\delta}\right)$ prevails under high cost arbitration, $(\alpha, \delta) \in H$; when $(\alpha, \delta) \in M$ the split is $\left(\frac{2(1-\alpha)}{2-\alpha}, \frac{\alpha}{2-\alpha}\right)$.

It is now immediate to observe that an efficient use of arbitration is not assured in equilibrium.

Corollary 7 Equilibrium AND EFfiCIEnCy ARE NOT ALIGNed: Efficiency demands that arbitration prevails if and only if $\alpha \geq \delta$. When $\delta \leq \frac{2}{3}$, $\alpha \in\left[\delta, 1+2 \delta-\sqrt{1+4 \delta^{2}}\right]$ an inefficient negotiated agreement is reached. When $\delta>\frac{2}{3}$ and $\alpha \in\left[1+2 \delta-\sqrt{1+4 \delta^{2}}, \delta\right]$ arbitration is used inefficiently.

We now turn to examine the consequences of requiring consensus to appoint the arbitrator.

\section{Pragmatic Arbitration by Consensus}

When consensus is required to terminate the negotiation and bring in the arbitrator, arbitration becomes a joint outside option. Consequently, when the first mover wishes to appoint the arbitrator, her bargaining power - that again arises from her control of the rate at which payoffs are discounted is limited by the veto power of the opponent. In equilibrium, arbitration is rejected if the responder expects greater payoffs from continuing the negotiation than from the arbitrated settlement.

One may think that, if a player has the right to veto arbitration, she will use this right when the arbitrated outcome is unfavorable, neutralizing the presence of the arbitrator. Contrary to this intuition, we show that the presence of an arbitrator in the background remains a strong influence on the bargaining outcome, even when the consent of both parties is required. 
The characterization of equilibria in the present environment is given through Lemmata 8 to 10 that establish optimal actions in a way analogous to Lemmata 2 to 5 of the previous section. Since proposing arbitration is a dominated action in states where the optimal reply of the opponent is to reject it, we can safely omit acceptance rules in describing the optimal actions of players at each state of the game. Thus we will simply specify the optimal action of the first mover at each bargaining state. The detailed proofs are in the appendix. They follow along the same arguments used to prove the analogous results in the previous section. They are, however, a bit more involved since the constraints imposed by the rule of consensus must be taken into consideration. The action leading to arbitration is taken in fewer states than in the game with unilateral arbitration: not only the costs of arbitration must be sufficiently low, in addition, the approval of Player 2 must be granted.

Our first observation, however, is that things do not change in states where the responding agent has received accumulated concessions that exceed the present value of obtaining all remaining surplus in one period of delay. In these states, if the proposal of arbitration is not a dominated action, its acceptance is assured. Hence the actions that the proposer takes in equilibrium are not affected by the requirement of consensus. Whatever action was optimal under unilateral arbitration remains optimal when arbitration needs consensus.

Lemma 8 Consider states where $x_{2} \geq \delta\left(x_{2}+X\right)$. If opting out is the optimal action of player 1 in unilateral arbitration, the optimal action under consensus arbitration is to propose arbitration. Otherwise, the optimal concessions of player 1 under consensus or unilateral arbitration coincide.

We now consider states where one of the two players has received concessions that exceed $\frac{\delta}{1+\delta}$.

Lemma 9 In states where $x_{i}<\delta\left(x_{i}+X\right), i=1,2$ and either $x_{1} \geq \frac{\delta}{1+\delta}$ or $x_{2} \geq \frac{\delta}{1+\delta}$ the optimal actions of Player 1 are as follows.

1. If $x_{1} \geq \frac{\delta}{1+\delta}$ a concession $X$ if either $\left.i\right) \alpha \leq \max \left\{\frac{2 \delta}{1+2 \delta}, \delta\right\}$, or ii) $\max \left\{\frac{2 \delta}{1+2 \delta}, \delta\right\}<\alpha \leq \frac{2 \delta}{1+\delta}$ with $x_{1} \geq \alpha\left(x_{1}+\frac{X}{2}\right)$, or iii) $\max \left\{\frac{2 \delta}{1+2 \delta}, \delta\right\}<$ $\alpha \leq \frac{2 \delta}{1+\delta}$ with $x_{1}<\alpha\left(x_{1}+\frac{X}{2}\right)$ and $\delta^{2}\left(x_{2}+X\right) \geq \alpha\left(x_{2}+\frac{X}{2}\right)$; a concession $C_{1}^{A}$ if either iv) $\max \left\{\frac{2 \delta}{1+2 \delta}, \delta\right\}<\alpha \leq \frac{2 \delta}{1+\delta}$ with $x_{1}<\alpha\left(x_{1}+\frac{X}{2}\right)$ and 
$\delta^{2}\left(x_{2}+X\right)<\alpha\left(x_{2}+\frac{X}{2}\right)$ or $\left.v\right) \frac{2 \delta}{1+\delta}<\alpha$ and $\alpha\left(x_{1}+\frac{X}{2}\right)<\delta\left(x_{1}+X-C_{1}^{A}\right) ;$ otherwise propose arbitration.

2. If $x_{2} \geq \frac{\delta}{1+\delta}$ to concede nothing if either i) $\alpha \leq \max \left\{\frac{2 \delta}{1+2 \delta}, \delta\right\}$ or ii) when $x_{2} \leq \alpha\left(x_{2}+\frac{X}{2}\right)$ and $\delta^{2}\left(x_{1}+X\right) \geq \alpha\left(x_{1}+\frac{X}{2}\right)$. Otherwise $a$ concession $C_{1}^{A}$ whenever $\alpha\left(x_{1}+\frac{X}{2}\right)<\delta\left(x_{1}+X-C_{1}^{A}\right)$ or else propose arbitration.

And the characterization of optimal actions is completed with our next result.

Lemma 10 In states such that $x_{i}<\frac{\delta}{1+\delta} i=1,2$ the optimal actions of Player 1 are:

1. If $\alpha \leq \max \left\{\frac{2 \delta}{1+2 \delta}, \delta\right\}$ a concession $C_{1}^{N}$.

2. If $\max \left\{\frac{2 \delta}{1+2 \delta}, \delta\right\}<\alpha \leq \frac{2 \delta}{1+\delta}$ and $\alpha\left(x_{i}+\frac{X}{2}\right) \geq \delta^{2}\left(x_{i}+X\right) i=1,2 a$ concession $C_{1}=\operatorname{Max}\left\{C_{1}^{A}, C_{1}^{N}\right\}$ whenever $\alpha\left(x_{1}+\frac{X}{2}\right) \leq \delta\left(x_{1}+X-C_{1}\right)$ or else propose arbitration.

3. If $\max \left\{\frac{2 \delta}{1+2 \delta}, \delta\right\}<\alpha \leq \frac{2 \delta}{1+\delta}$ and $\alpha\left(x_{i}+\frac{X}{2}\right)<\delta^{2}\left(x_{i}+X\right)$ for some $i$, a concession $C_{1}^{N}$ if $x_{1} \leq \frac{2 \delta^{2}-\alpha}{\alpha(1+\delta)}$; otherwise a concession $C_{1}=\operatorname{Max}\left\{C_{1}^{N}, C_{1}^{A}\right\}$.

4. If $\frac{2 \delta}{1+\delta}<\alpha$ a concession $C_{1}^{A}$ if $\alpha\left(x_{1}+\frac{X}{2}\right) \leq \delta\left(x_{1}+X-C_{1}^{A}\right)$ or else to propose arbitration.

To characterize the unique equilibrium outcome it suffices to consider the partition of the set of parameters induced by the optimal action scenarios of Lemma 10 at the initial state $(0,0,1)$. The parameters $(\alpha, \delta)$ for which $C_{i}^{N}=\frac{\delta}{1+\delta}$ is the optimal action are in the set

$$
H^{C}=H \cup\left\{(\alpha, \delta) \text { such that } \alpha \leq \min \left\{2 \delta^{2}, \frac{2 \delta}{1+\delta}\right\}\right\} .
$$

And the optimal action is $C_{i}^{A}=\frac{\alpha}{2-\alpha}$ at parameters that lie in

$$
M^{C}=M /\left\{(\alpha, \delta) \text { such that } \alpha \leq \min \left\{2 \delta^{2}, \frac{2 \delta}{1+\delta}\right\}\right\} .
$$


When $(\alpha, \delta) \notin H^{C} \cup M^{C}$, the optimal action is to propose arbitration. Figure 4 displays the sets $H^{C}$ and $M^{C}$.

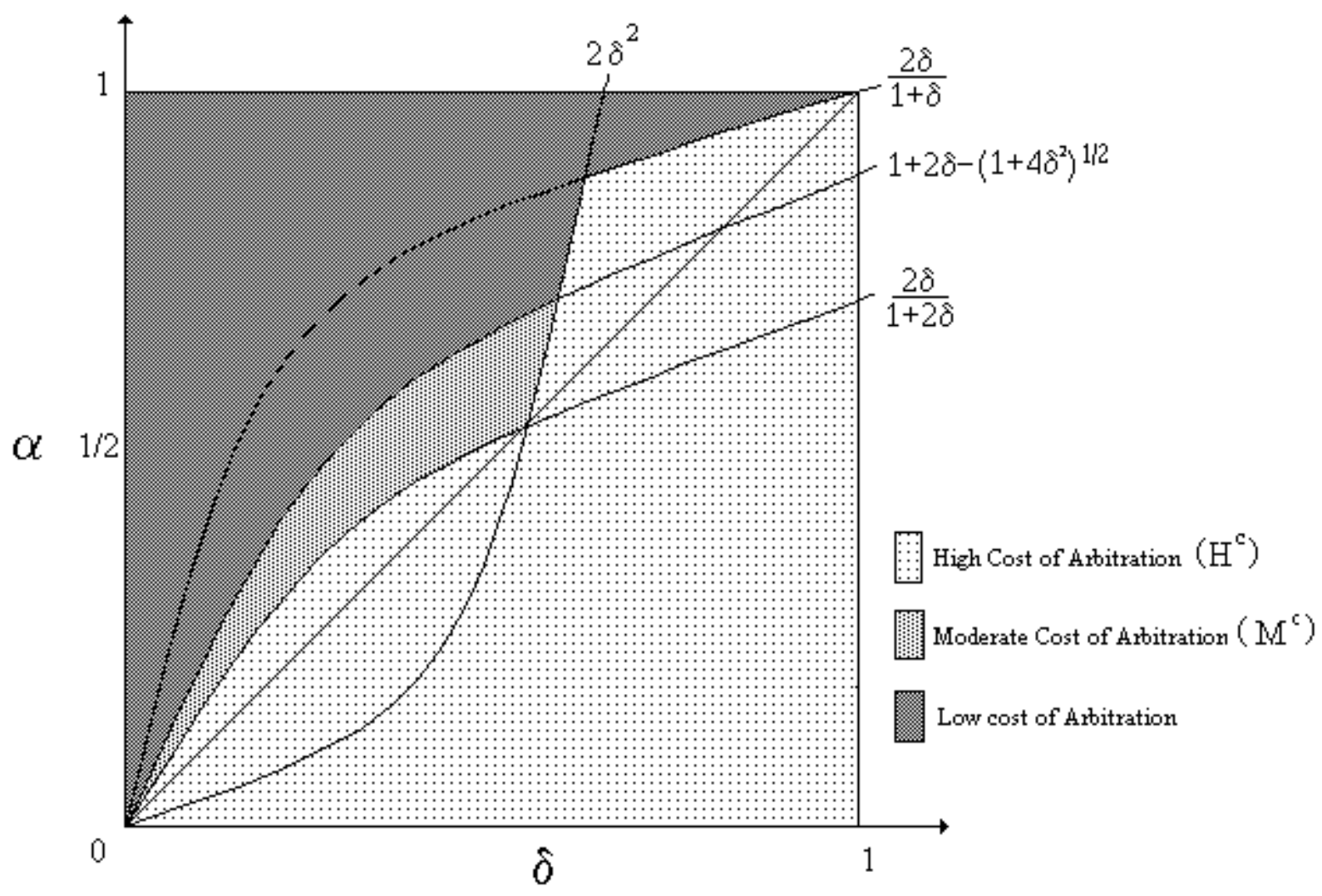

Figure 4

The unique equilibrium outcome for all possible parameters $\alpha$ and $\delta$, is now immediate from Lemma 10 and Lemma 9.

Proposition 11 pragmatic arbitration By COnSEnsus: When a pragmatic arbitrator - allocating shares $A_{i}=x_{i}+\frac{X}{2}$ - is appointed by consensus, there is a unique equilibrium. Arbitration prevails if and only if it has low cost, $(\alpha, \delta) \notin H^{C} \cup M^{C}$, and this outcome occurs at $t=0$. Otherwise a negotiated agreement is reached at $t=1$. The negotiated partition $\left(\frac{1}{1+\delta}, \frac{\delta}{1+\delta}\right)$ prevails under high cost arbitration, $(\alpha, \delta) \in H^{C}$; otherwise, when $(\alpha, \delta) \in$ $M^{C}$ the split is $\left(\frac{2(1-\alpha)}{2-\alpha}, \frac{\alpha}{2-\alpha}\right)$.

The following is now immediate. 
Corollary 12 too many negotiated Agreements: Arbitration is never used inefficiently since a negotiated agreement surely prevails when $\alpha<\delta$. Still, efficiency and equilibrium remain unaligned, since $H^{C} \cup M^{C}$ contains a substantial region where arbitration is the superior procedure to solve the dispute, $\alpha>\delta$, and yet players reach a negotiated agreement incurring the higher cost $(1-\delta)$.

\section{Arbitration on Principle}

To complete our exploration we now consider arbitrators that act on principle, ignoring the negotiation process that precedes their appointment, and imposing a fair settlement independently of the state that the negotiations have reached. That is, at all states $\left(x_{1}, x_{2}, X\right)$, the arbitrated share of both players is

$$
A_{i}=\frac{1}{2}
$$

When bargainers interact with such an arbitrator in the background, either they ignore her, or they waste no time in appointing her. It turns out that there is a simple threshold that separates scenarios for which agents opt out to arbitration, below that threshold, arbitration is irrelevant and agents behave as in Proposition 1. Furthermore, the consensus required to bring in the arbitrator is irrelevant, the same outcome prevails if agents can do it unilaterally or when they need the opponent's approval. This results are stated formally as Proposition 13 that follows. The proof is in the Appendix.

Proposition 13 ARBITRATION ON PRINCIPLE. Assume that the arbitrated settlement is fixed at $\left(\frac{1}{2}, \frac{1}{2}\right)$. A unique equilibrium outcome prevails independently of whether the decision to opt out to arbitration is unilateral or by consensus. If $\alpha \leq \frac{2 \delta}{1+\delta}$ then a negotiated agreement $\left(\frac{1}{1+\delta}, \frac{\delta}{1+\delta}\right)$ is reached at $t=1$; otherwise arbitration prevails at $t=0$.

With a complete characterization of equilibrium outcomes under each arbitration system we may now compare their relative performance.

\section{Comparing Arbitration Systems}

Let us first consider arbitration systems with a unilateral appointment rule. In this case, when $\alpha \in\left[\frac{2 \delta}{1+2 \delta}, 1+2 \delta-\sqrt{1+4 \delta^{2}}\right]$ a pragmatic arbitrator is 
not irrelevant, but agents do not appoint her either and a negotiated agreement is reached. In contrast, at this set of scenarios, an arbitrator that acts on principle is appointed. Observe that, as a consequence, the range of scenarios in which arbitration is inefficiently used is greatly reduced by the pragmatic conduct of the arbitrator.

When the arbitrator is pragmatic and mutual consent is required the range of scenarios at which agents reach negotiated agreements is maximal. In this case, in addition to scenarios at which negotiated agreements prevail with a unilateral rule, negotiated agreements are reached at $(\delta, \alpha)$ such that $\alpha \in\left[1+2 \delta-\sqrt{1+4 \delta^{2}}, \min \left\{2 \delta^{2}, \frac{2 \delta}{1+2 \delta}\right\}\right]$.

Hence, as the arbitrator's conduct changes from acting on principle into acting pragmatically the range of scenarios at which the arbitrator is not appointed increases. And, similarly, negotiated agreements are more likely as we move from unilateral pragmatic arbitration into pragmatic arbitration by mutual consent.

An increase the range of parameters at which negotiated agreements prevail does not necessarily implies an increase in efficiency, tough. The efficiency performance of each arbitration system depends on the likelihood of the different cost configurations.

When the distributions of the costs of negotiation and arbitration are known, the (ex-ante) expected performance for each system of arbitration can be evaluated based on ex-ante expected benefits.

Assume that negotiation and arbitration costs are distributed according to some joint distribution $F(\alpha, \delta)$ on $[0,1]^{2}$. Then the ex-ante benefits of each system can be measured as follows.

Full efficiency is attained when the cheaper procedure is used for each realization $(\alpha, \delta)$. This yields ex-ante benefits

$$
W^{E}=\int_{\delta \geq \alpha} \delta d F+\int_{\delta<\alpha} \alpha d F
$$

The expected benefits in the absence of an arbitrator are

$$
\left.W^{N}=\int_{\text {all }} \delta, \delta\right) \text { } \delta f F .
$$

The expected benefits under the unilateral pragmatic arbitration system are

$$
W^{U}=\int_{(\alpha, \delta) \in H \cup M} \delta d F+\int_{((\alpha, \delta) \notin H \cup M} \alpha d F ;
$$


and for pragmatic arbitration by consensus they are

$$
W^{C}=\int_{(\alpha, \delta) \in H^{C} \cup M} \delta d F+\int_{(\alpha, \delta) \notin H^{C} \cup M} \alpha d F .
$$

When the arbitrator acts on principle the expected benefirs are

$$
W^{O P}=\int_{(\alpha, \delta) \in H} \delta d F+\int_{(\alpha, \delta) \notin H} \alpha d F .
$$

In what follows we present two examples pointing out that in regular environments none of the three systems of arbitration can be dismissed a priori. Each might be the (second best) optimal system under natural conditions.

Our first example considers environments where both costs are i.i.d. with positive symmetric density.

Example 14 Assume that arbitration and negotiation costs are independently and identically distributed in $[0,1]$ with a distribution with density

$$
f^{\rho}(u)=\frac{u^{\rho-1}(1-u)^{\rho-1}}{K(\rho)}
$$

where $K(\rho)=\int_{0}^{1} u^{\rho-1}(1-u)^{\rho-1}$ and $\rho \geq 1$. Table 1 presents the ex-ante expected benefits for different values of the parameter $\rho$. For each environment, the optimal arbitration system is denoted with a $*$-superscript:

$\begin{array}{llllll}\rho & W^{E} & W^{N} & W^{U} & W^{C} & W^{O P} \\ 1 & .666 & .5 & .660 & .662^{*} & .657 \\ 2 & .628 & .5 & .622^{*} & .620 & .621 \\ 5 & .586 & .5 & .579 & .576 & .582^{*}\end{array}$

Table 1

i.i.d. costs with densities $f^{\rho}(u)=\frac{u^{\rho-1}(1-u)^{\rho-1}}{K(\rho)}$

We now examine an example where the distributions of costs have upwards or downwards biases. We consider environments where both costs tend to be high, environments where both tend to be low; and two asymmetric environments where one cost tends to be high and the other tends to be low. 
Example 15 Assume that each cost is independently drawn from a distribution with a density either $f(x)=2 x$, or $f(x)=2(1-x)$. Table 2 displays the expected benefits under each system for each of the four possible joint densities.

$\begin{array}{llllll}f(\alpha, \delta) & W^{E} & W^{N} & W^{U} & W^{C} & W^{O P} \\ 4 \alpha \delta & .8 & .666 & .790 & .794^{*} & .778 \\ 4(1-\alpha)(1-\delta) & .466 & .333 & .461 & .460 & .463^{*} \\ 4(1-\alpha) \delta & .7 & .666 & .696^{*} & .610 & .691 \\ 4 \alpha(1-\delta) & .7 & .333 & .696 & .696 & .697^{*}\end{array}$

Table 2

Asymmetric Environments

From the preceding examples we conclude that policy prescriptions concerning arbitrator's conduct or appointment rules require precise information on the distribution of negotiation and arbitration cost.

\section{Conclusions}

Aiming to explore the impact of different arbitration systems on negotiations, we have characterized the equilibrium of concession bargaining games with arbitration in the background. We summarize our findings in the following three points:

1. Arbitration might alter the negotiated partition of the surplus relative to the situation in which it is unavailable. This occurs only if the arbitrated partition of the surplus is endogenous and the relative cost of arbitration is not too high, since arbitration turns irrelevant when it is excessively costly. When arbitration is relevant, the negotiation positions of the players approach those sustained by the arbitrator and the first mover advantage is reduced. If the cost of arbitration is sufficiently low players immediately resort to arbitration, and an equal split of the surplus prevails.

2. The requisite of mutual consent is of great consequence if the arbitrator is pragmatic, but it is irrelevant when the arbitrator acts on principle. 
3. Arbitration cannot assure full efficiency. What system of arbitration promotes the greater ex-ante gain in efficiency depends on the distribution of negotiation and arbitration costs.

\section{Appendix}

\section{Unilateral Arbitration}

Proof of Lemma 2: Player 1 chooses one of the following alternatives: a) concede $X$ and receive a payoff of $x_{1} ; \mathrm{b}$ ) concede nothing obtaining at most $\delta\left(x_{1}+X\right)$ in the continuation; c) concede $0<C_{1}<X$, obtaining at most $\delta\left(x_{1}+X-C_{1}\right)$; d) Opt out to arbitration, which pays $\alpha\left(x_{1}+\frac{X}{2}\right)$.

Since $x_{1} \geqslant \delta\left(x_{1}+X\right)>\delta\left(x_{1}+X-C_{1}\right)$ the optimal action is to concede $X$ provided that $x_{1}>\alpha\left(x_{1}+\frac{X}{2}\right)$. For $x_{1} \geqslant \delta\left(x_{1}+X\right)$ the inequality $x_{1} \geq$ $\alpha\left(x_{1}+\frac{X}{2}\right)$ is equivalent to $\alpha \stackrel{2}{\leq} \frac{2 \delta}{\delta+1}$. And if $\alpha>\frac{2 \delta}{\delta+1}$ then player 1 opts out in states where $\alpha\left(x_{1}+\frac{X}{2}\right)>x_{1}$ since opting out dominates making any concession.

Proof of Lemma 3: In scenario 1) Player 2 faces the situation analyzed in Lemma 21 ); hence her optimal action is to concede $X$. Now consider Player 1: if she concedes nothing, player 2 will concede $X$ in the following period, and 1 obtains $\delta\left(x_{1}+X\right)$. This payoff is greater than what 1 would get if she concedes $X$ since $\delta\left(x_{1}+X\right)>x_{1}$. Likewise $\delta\left(x_{1}+X\right)>\delta\left(x_{1}+X-C_{1}\right)$ implying that any $C_{1}, 0<C_{1}<X$ is dominated as well. To rule out arbitration simply observe that to call the arbitrator is in Player 1's interest only if $\alpha\left(x_{1}+\frac{X}{2}\right) \geq \delta\left(x_{1}+X\right)$, and note that $x_{1}<\delta\left(x_{1}+X\right)$ and $\alpha \leq \frac{2 \delta}{1+\delta}$ imply that the preceding inequality is impossible. To check 2 ) note that by Lemma 2 2) Unless she receives a sufficient concession Player 2 will opt out in the continuation. Thus the action of Player 1 must be either to opt out to arbitration right away or to concede something that prevents arbitration, the minimal concession achieves that is $C^{A}$. Thus Player 1 opts out it if and only if $\alpha\left(x_{1}+\frac{X}{2}\right) \geq \delta\left(x_{1}+X-C_{1}^{A}\right)$ and concedes $C_{1}^{A}$ otherwise. Notice that $C_{1}^{A}=0$ for the states satisfying $x_{1}>\alpha\left(x_{1}+\frac{X}{2}\right)$.

Proof of Lemma 4: 1) Player 1 picks an action among the following alternatives: a) concede $X$ and obtain a payoff of $x_{1}$; b) concede $C_{1} \geq \tilde{C}_{1}$ and obtain $\delta\left(x_{1}+X-C_{1}\right)$, where $\tilde{C}_{1}$ is the minimal concession that leads the game to a state where Lemma 31 ) applies and 2 concedes all the contested 
surplus at $t+1$, i.e. $x_{2}+\tilde{C}_{1}=\delta\left(x_{2}+X\right)$; c) concede $0 \leq C_{1}<\tilde{C}_{1}$; and d) propose arbitration, that yields payoff of $\alpha\left(x_{1}+\frac{X}{2}\right)$.

First of all note that $\mathrm{b})$ is dominated by a): since $x_{1} \geq \frac{\delta}{1+\delta}>\delta\left(x_{1}+\right.$ $\left.X-\tilde{C}_{1}\right)>\delta\left(x_{1}+X-C_{1}\right)$. Next we check that a) dominates c) as well. Consider $C_{1}<\widetilde{C}_{1}$ that leads to a state where Lemma 21 ) applies. Player 2 concedes nothing at her turn and Player 1 obtains $\delta^{2} x_{1}$; that is dominated by a). Hence $C_{1}$ must be small enough so that the subsequent bargaining state still lies in the set of bargaining states that we are presently examining. Following such $C_{1}<\widetilde{C}_{1}, 1$ can expect from 2 at most $\widetilde{C}_{2}$, the concession that leaves Player 1 ready to finish the game at her next turn. Thus $C_{1}<\tilde{C}_{1}$ pays 1 at most $\delta^{2}\left(x_{1}+\tilde{C}_{2}\right)$. Substituting $\widetilde{C}_{2}=\delta\left(x_{1}+X\right)-x_{1}$, we obtain that $x_{1} \geq \delta^{2}\left(x_{1}+\tilde{C}_{2}\right)$ is equivalent to $x_{1} \geqslant \delta^{3}\left(x_{1}+X\right)$ and therefore a) dominates c) in states that satisfy the later inequality. A recursive argument completes the proof of the claim. Given $\delta$ there is a natural number such that $\delta^{n+1}\left(x_{1}+X\right)<x_{1}<\delta^{n}\left(x_{1}+X\right)$. Assume that in bargaining states satisfying $x_{1}<\delta\left(x_{1}+X\right), x_{2}<\delta\left(x_{2}+X\right), x_{1} \geq \frac{\delta}{1+\delta}$ and $\delta^{n+1}\left(x_{1}+X\right)<x_{1}$, conceding $X$ dominates any other partial concession. In states such that $x_{1}<\delta\left(x_{1}+X\right)$, $x_{2}<\delta\left(x_{2}+X\right), x_{1} \geq \frac{\delta}{1+\delta}$ and $x_{1}<\delta^{n}\left(x_{1}+X\right)$ the concession that player 1 can expect in the following from player 2 is no greater than $C_{2}$ such that $x_{1}+C_{2}=\delta^{n}\left(x_{1}+X\right)$. Hence, the expected payoff of from a concession smaller than $X$, is no greater than $\delta^{2}\left(x_{1}+C_{1}\right)=\delta^{2+n}\left(x_{1}+X\right)<\delta^{n+1}\left(x_{1}+X\right)<x_{1}$ so that 1 is better of conceding $X$.

Next, we show that when $\alpha \leq \frac{2 \delta}{1+2 \delta}$ a) dominates $\mathrm{d}$ ) because $x_{1} \geq \alpha\left(x_{1}+\right.$ $\left.\frac{X}{2}\right)$. First note that $\alpha \leq \frac{2 \delta}{1+2 \delta}$, i.e. $\frac{1}{1+\delta} \leq \frac{2(1-\alpha)}{2-\alpha}$, implies that if $x_{2}<\delta\left(x_{2}+X\right)$, $x_{1}<\delta\left(x_{1}+X\right)$ and $x_{1} \geq \frac{\delta}{1+\delta}$ then $x_{1} \geq \alpha\left(x_{1}+\frac{X}{2}\right)$ since $(1-\alpha) x_{1} \geq$ $(1-\alpha) \frac{\delta}{1+\delta} \geq \frac{\alpha}{2(1+\delta)} \geq \frac{\alpha}{2} X$.

The optimal actions of Player 1 for the parameters $\frac{2 \delta}{2 \delta+1}<\alpha \leq \frac{2 \delta}{\delta+1}$ are easily proved. If $x_{1} \geq \alpha\left(x_{1}+\frac{X}{2}\right)$ a) clearly dominates d) and the other alternatives and if $x_{1}<\alpha\left(x_{1}+\frac{X}{2}\right)$ opting out is the preferred action of Player 1 .

1. iii) follows from Lemma 32 ).

2) Is immediate from 1$)$.

Proof of Lemma 5: 1) If $\alpha \leq \frac{2 \delta}{1+2 \delta}$ a concession $C_{1}^{N}$ assures to 1 a payoff $\frac{\delta}{1+\delta}$ since Lemma 4 1) applies to Player 2 in the continuation so that she responds conceding the rest of the pie. To concede more than $C_{1}^{N}$ is clearly dominated. 
To concede less is also dominated; in that case, at the new bargaining state, Player 1 cannot expect to receive more than $C_{2}^{N}$, such that $x_{1}+C_{2}^{N}=\frac{\delta}{1+\delta}$ so that by conceding less than $C_{1}^{N}$, player 1 can get, at most, $\frac{\delta^{3}}{1+\delta}<\frac{\delta}{1+\delta}$. Arbitration is dominated by $C_{1}^{N}$ provided that $\frac{\delta}{1+\delta} \geq \alpha\left(x_{1}+\frac{X}{2}\right)$, which is true when $\alpha \leq \frac{2 \delta}{2 \delta+1}$ : Simply note that $\alpha\left(x_{1}+\frac{X}{2}\right) \leq \alpha\left(\frac{\delta}{1+\delta}+\frac{1}{2}\left(1-\frac{\delta}{1+\delta}\right)\right)=$ $\frac{\alpha}{2} \frac{2 \delta+1}{1+\delta}$ and that $\frac{\alpha}{2} \frac{2 \delta+1}{1+\delta}<\frac{\delta}{1+\delta}$ for all $\alpha<\frac{2 \delta}{2 \delta+1}$.

2. Note first that opting out is dominated since either $\alpha\left(x_{1}+\frac{X}{2}\right) \leq \frac{\delta}{1+\delta}$ or $\alpha\left(x_{1}+\frac{X}{2}\right) \leq \delta\left(x_{1}+X-C_{1}^{A}\right)$. Moreover, while conceding $C_{1}^{\prime}>C_{1}$ is obviously dominated, a concession $C_{1}^{\prime}<C_{1}$ leads the game to the state where player 2 either opts out to arbitration or concedes $C_{2}=\operatorname{Max}\left[C_{2}^{A}, C_{2}^{N}\right]$. The first alternative pays $\delta \alpha\left(x_{1}+\frac{X-C_{1}^{\prime}}{2}\right)<\alpha\left(x_{1}+\frac{X}{2}\right) \leq \delta\left(x_{1}+X-C_{1}\right)$, and the second pays, at most, $\operatorname{Max}\left\{\frac{\delta^{3}}{1+\delta}, \frac{\delta^{2} \alpha}{2-\alpha}\right\}$ and either $\operatorname{Max}\left\{\frac{\delta^{3}}{1+\delta}, \frac{\delta^{2} \alpha}{2-\alpha}\right\} \leq$ $\frac{2 \delta(1-\alpha)}{2-\alpha} \leq \delta\left(x_{1}+X-C_{1}^{A}\right)$ or $\operatorname{Max}\left\{\frac{\delta^{3}}{1+\delta}, \frac{\delta^{2} \alpha}{2-\alpha}\right\} \leq \frac{\delta}{1+\delta}$. Therefore Player 1 optimally concedes $C_{1}$.

If $\frac{2 \delta}{\delta+1}<\alpha$ then a concession $C_{1}^{N}$ cannot not induce a total concession by 2 in the continuation: In state $\left(x_{1}, \frac{\delta}{1+\delta}, X^{\prime}\right)$ Player 2 prefers a total concession over arbitration if $\frac{\delta}{1+\delta} \geq \alpha\left(\frac{\delta}{1+\delta}+\frac{X^{\prime}}{2}\right)$, while $x_{i}<\frac{\delta}{1+\delta}$ implies that $X^{\prime}=$ $1-x_{i}-\frac{\delta}{1+\delta} \geq \frac{1-\delta}{1+\delta}$, which in turn implies that $\alpha \leq \frac{2 \delta}{1+\delta}$. Hence, Player 1 must chose either arbitration or $C_{1}^{A}$, and concession $C_{1}^{A}$ dominates arbitration if $\alpha\left(x_{1}+\frac{X}{2}\right) \leq \delta\left(x_{1}+X-C_{1}^{A}\right)$.

\section{Arbitration by Consensus}

Proof of Lemma 8: It suffices to observe that the proposal of arbitration is always accepted by 2 whenever opting out is the optimal action of Player 1 under unilateral arbitration.

If $\alpha \leq \delta$ opting out is never optimal (see Lemma 2.1 and Lemma 3.1). And if $\alpha>\delta$ and Player 1 proposes arbitration, Player 2 will always accept since $\alpha\left(x_{2}+\frac{X}{2}\right)>\delta x_{2}$.

Proof of Lemma 9:1) The same arguments used in the proof of Lemma 4 establish that the optimal action is either a) concede $X$ and obtain a payoff of $x_{1}$ or $\mathrm{d}$ ) propose arbitration, that yields payoff of $\alpha\left(x_{1}+\frac{X}{2}\right)$, provided that 2 accepts it.

Next, we show that when $\alpha \leq \frac{2 \delta}{1+2 \delta}=\max \left\{\frac{2 \delta}{1+2 \delta}, \delta\right\}$ a) dominates d) because $x_{1} \geq \alpha\left(x_{1}+\frac{X}{2}\right)$. First note that $\alpha \leq \frac{2 \delta}{1+2 \delta}$, i.e. $\frac{1}{1+\delta} \leq \frac{2(1-\alpha)}{2-\alpha}$, implies that if $x_{2}<\delta\left(x_{2}+X\right), x_{1}<\delta\left(x_{1}+X\right)$ and $x_{1} \geq \frac{\delta}{1+\delta}$ then $x_{1} \geq \alpha\left(x_{1}+\frac{X}{2}\right)$ 
since $(1-\alpha) x_{1} \geq(1-\alpha) \frac{\delta}{1+\delta} \geq \frac{\alpha}{2(1+\delta)} \geq \frac{\alpha}{2} X$. If $\alpha \leq \delta=\max \left\{\frac{2 \delta}{1+2 \delta}, \delta\right\}$ we find states for which $x_{1}<\alpha\left(x_{1}+\frac{X}{2}\right)$. However, Player 2 rejects the arbitration proposal since $\alpha\left(x_{2}+\frac{X}{2}\right) \leq \delta^{2}\left(x_{2}+X-C_{2}^{A}\right)$.

If $\frac{2 \delta}{1+\delta} \geq \alpha>\max \left\{\frac{2 \delta}{1+2 \delta}, \delta\right\}$, then arbitration is no longer unanimously dominated at all states under consideration. Total concession obviously dominates arbitration for states where $x_{1} \geq \alpha\left(x_{1}+\frac{X}{2}\right)$. In states such that $x_{1}<\alpha\left(x_{1}+\frac{X}{2}\right)$, Player 1 prefers arbitration over conceding $X$. Player 2 acceptance is guaranteed for states satisfying $\alpha\left(x_{2}+\frac{X}{2}\right) \geq \delta^{2}\left(x_{2}+X\right)$. Otherwise Player 1 concedes $X$.

Let us now check the optimal actions of Player 1 in states where Player 2 (optimally) proposes arbitration. Note that concession $C_{1}^{A}$ assures that Player 2 optimally concedes the rest of the pie next period. A concession $C_{1}>C_{1}^{A}$ is clearly dominated. On the other hand the payoff from $C_{1}<C_{1}^{A}$ is at most $\alpha \delta\left(x_{1}+\frac{X-C_{1}}{2}\right)<\alpha\left(x_{1}+\frac{X}{2}\right)$. And finally, to propose arbitration is dominated by $C_{1}^{A}$ since $\alpha>\frac{2 \delta}{1+2 \delta}$, i.e. $\frac{1}{1+\delta} \cdot \geq \frac{2(1-\alpha)}{2-\alpha}$, implies that $\alpha\left(x_{1}+\frac{X}{2}\right) \leq$ $\alpha\left(\frac{\alpha(1+\delta)-\delta}{\alpha(1+\delta)}\right)<\frac{2 \delta(1-\alpha)}{2-\alpha} \leq \delta\left(x_{1}+X-C_{1}^{A}\right)$.

The result for scenario v) follows from Lemma 8. Simply observe that whenever Player 1 proposes arbitration, Player 2 accepts since $\alpha\left(x_{2}+\frac{X}{2}\right) \geq$ $\delta^{2}\left(x_{2}+X-C_{2}^{A}\right)$.

2) Follows from immediately from 1).

Proof of Lemma 10:1) A concession $C_{1}^{N}$ assures to 1 a payoff $\frac{\delta}{1+\delta}$ provided that Lemma 9 1. i) applies to Player 2 in the continuation so that she responds conceding the rest of the pie. To rule out concessions $C_{1} \neq C_{1}^{N}$ we argue as in the proof of Lemma 5. It remains to be checked that arbitration is dominated as well. Arbitration is dominated by $C_{1}^{N}$ provided that $\frac{\delta}{1+\delta} \geq$ $\alpha\left(x_{1}+\frac{X}{2}\right)=\frac{\alpha}{2}\left(1+x_{1}-x_{2}\right)$ and that it suffices that $\frac{\delta}{1+\delta} \geq \frac{\alpha}{2}\left(1+x_{1}\right)$ which is equivalent to $x_{1} \leq \frac{\alpha-2 \delta(1-\alpha)}{\alpha(1+\delta)}$. Assume that $\alpha \leq \max \left\{\frac{2 \delta}{1+2 \delta}, \delta\right\}$ holds and $\alpha\left(x_{1}+\frac{X}{2}\right) \geq \frac{\delta}{1+\delta}$, acceptance by Player 2 requires that $\alpha\left(x_{2}+\frac{X}{2}\right) \geq \frac{\delta^{2}}{1+\delta}$. Both inequalities combined imply that $\alpha>\delta$. Hence, $\delta<\alpha<\frac{2 \delta}{2 \delta+1}$ but the later inequality contradicts that $\alpha\left(x_{1}+\frac{X}{2}\right) \geq \frac{\delta}{1+\delta}$ : Simply note that $\alpha\left(x_{1}+\frac{X}{2}\right) \leq \alpha\left(\frac{\delta}{1+\delta}+\frac{1}{2}\left(1-\frac{\delta}{1+\delta}\right)\right)=\frac{\alpha}{2} \frac{2 \delta+1}{1+\delta}$ and that $\frac{\alpha}{2} \frac{2 \delta+1}{1+\delta}<\frac{\delta}{1+\delta}$ for all $\alpha<\frac{2 \delta}{2 \delta+1}$.

2) Note that if Player 1 proposes arbitration Player 2 will accept since either $\alpha\left(x_{2}+\frac{X}{2}\right)>\delta x_{2}$ or $\alpha\left(x_{2}+\frac{X}{2}\right) \geqslant \delta^{2}\left(x_{2}+X\right)>\delta^{2}\left(x_{2}+X-C_{i}\right)$. By the same arguments used in the proof of Lemma 5 we prove that Player 1 concedes $C_{1}=\operatorname{Max}\left\{C_{1}^{A}, C_{1}^{N}\right\}$ whenever $\alpha\left(x_{1}+\frac{X}{2}\right) \leqslant \delta\left(x_{1}+X-C_{1}\right)$ or else 
she proposes arbitration.

3) If $x_{1} \leqslant \frac{2 \delta^{2}-\alpha}{\alpha(1+\delta)}$ a concession of $C_{1}^{N}$ gives Player 1 a payoff of $\frac{\delta}{1+\delta}$ since Player 2 concedes $X$ in the following period (Lemma 9 1) iii). To concede more than $C_{1}^{N}$ is clearly a dominated option, and to concede $C_{1}^{\prime}<C_{1}^{N}$ leads the game to a state where Player 2 concedes, at most, $C_{2}=\operatorname{Max}\left\{C_{2}^{N}, C_{2}^{A}\right\}$. In those cases $\frac{\delta}{1+\delta}>\operatorname{Max}\left\{\frac{\delta^{3}}{1+\delta}, \frac{\delta^{2} \alpha}{2-\alpha}\right\} \geq \delta^{2}\left(x_{1}+X-C_{1}^{\prime}\right)$. Arbitration is also dominated since $\alpha\left(x_{1}+\frac{X}{2}\right) \leq \frac{\delta}{1+\delta}$ for $x_{1} \leq \frac{2 \delta^{2}-\alpha}{\alpha(1+\delta)}$.

Next we show that the optimal action of Player 1 is a concession $C_{1}=$ $\operatorname{Max}\left\{C_{1}^{N}, C_{1}^{A}\right\}$ whenever $x_{1}>\frac{2 \delta^{2}-\alpha}{\alpha(1+\delta)}$. To concede more than $C_{1}$ is easily ruled out. And to concede $C_{1}^{\prime}<C_{1}$ leads the game to a state where either Lemma 9.2 applies or still lies in the set of states that we are presently examining. If Player 2 makes a concession in the following period, Player 1 will get, at most, $\operatorname{Max}\left\{\frac{\delta^{3}}{1+\delta}, \frac{\delta^{2} \alpha}{2-\alpha}\right\}<\delta\left(x_{1}+X-C_{1}\right)$ and if Player 2 proposes arbitration, Player 1 will get $\delta \alpha\left(x_{1}+\frac{X-C_{1}^{\prime}}{2}\right)<\delta\left(x_{1}+X-C_{1}\right)$.

There are states where Player 1 prefers arbitration rather than conceding $C_{1}$. But Player 2 rejects this proposal since $\alpha\left(x_{2}+\frac{X}{2}\right)<\frac{\delta^{2}}{1+\delta}$.

4) Observe that if $\alpha>\frac{2 \delta}{1+\delta}$, then a concession $C_{1}^{N}$ cannot not induce a total concession by 2 in the continuation: In state $\left(x_{1}, \frac{\delta}{1+\delta}, X^{\prime}\right)$ Player 2 prefers total concession over arbitration if $\frac{\delta}{1+\delta} \geq \alpha\left(\frac{\delta}{1+\delta}+\frac{X^{\prime}}{2}\right)$, while $x_{i}<\frac{\delta}{1+\delta}$ implies that $X^{\prime}=1-x_{i}-\frac{\delta}{1+\delta} \geq \frac{1-\delta}{1+\delta}$, which in turn implies that $\alpha \leq \frac{2 \delta}{1+\delta}$. Hence, Player 1 must chose either arbitration or $C_{1}^{A}$, and concession $C_{1}^{A}$ dominates the proposal of arbitration if $\alpha\left(x_{1}+\frac{X}{2}\right) \leq \delta\left(x_{1}+X-C_{1}^{A}\right)$.

\section{Arbitration on Principle}

\section{Proof of Proposition 13:}

It is easy to check that when the payoffs from arbitration are fixed at $\frac{\alpha}{2}$, the optimal actions at each of the four possible state configurations are as stated in Claims 1 to 4.

Claim 1: Consider states where $x_{1} \geq \delta\left(x_{1}+X\right)$. A) Assume unilateral appointment. If $x_{1} \geq \frac{\alpha}{2}$, then Player 1 concedes $X$; otherwise Player 1 opts out to arbitration. B) Assume appointment by mutual consent. If $x_{1} \geq \frac{\alpha}{2}$ or $\delta x_{2} \geq \frac{\alpha}{2}$, then Player 1 concedes $X$; otherwise Player 1 proposes arbitration.

Claim 2: Consider states where $x_{1}<\delta\left(x_{1}+X\right)$ and $x_{2} \geq \delta\left(x_{2}+X\right)$. A) Assume unilateral appointment. A1) If $\frac{\delta}{1+\delta} \geq \frac{\alpha}{2}$ and $\delta\left(x_{1}+X\right) \geq \frac{\alpha}{2}$ Player 1 concedes nothing. A2) If $\frac{\delta}{1+\delta} \geq \frac{\alpha}{2}$ and $\delta\left(x_{1}+X\right)<\frac{\alpha}{2}$ Player 1 opts out 
. A3) And if $\frac{\delta}{1+\delta} \geq \frac{\alpha}{2}$ she opts out to arbitration. B) Assume appointment by mutual consent. If $\delta x_{2} \geq \frac{\alpha}{2}$ Player 1 concedes nothing; otherwise she proposes arbitration whenever $\delta\left(x_{1}+X\right)<\frac{\alpha}{2}$ or else she concedes nothing.

Claim 3: Consider states where $x_{i}<\delta\left(x_{i}+X\right), i=1,2$. A) Assume unilateral appointment. A1) Assume $x_{1} \geq \frac{\delta}{1+\delta}$.i) If $\frac{\delta}{1+\delta} \geq \frac{\alpha}{2}$ then Player 1 concedes $X$. ii) If $\frac{\delta}{1+\delta}<\frac{\alpha}{2}$ then Player 1 concedes $X$ whenever $x_{1} \geq \frac{\alpha}{2}$, otherwise she opts out. A2) Assume $x_{2} \geq \frac{\delta}{1+\delta}$. i) If $\alpha \leq \frac{2 \delta}{1+\delta}$ then Player 1 concedes nothing whenever $\delta\left(x_{1}+X\right) \geq \frac{\alpha}{2}$ or else opts out to arbitration. ii) If $\alpha>\frac{2 \delta}{1+\delta}$ Player 1 opts out to arbitration. B) Assume appointment by mutual consent. B1) Assume $x_{1} \geq \frac{\delta}{1+\delta}$. If $\alpha \leq \frac{2 \delta}{1+\delta}$ then Player 1 concedes $X$; otherwise she proposes arbitration. B2) Assume $x_{2} \geq \frac{\delta}{1+\delta}$. Then Player 1 concedes nothing if $\alpha \leq \frac{2 \delta}{1+\delta}$, otherwise she proposes arbitration.

Claim 4: Consider states such that $x_{i}<\frac{\delta}{1+\delta} i=1,2$. A) Assume unilateral appointment. If $\alpha \leq \frac{2 \delta}{1+\delta}$, then Player 1 concedes $C_{1}^{N}$; otherwise she opts out to arbitration. B) Assume appointment by mutual consent. If $\alpha \leq \frac{2 \delta}{1+\delta}$, then Player 1 concedes $C_{1}^{N}$; otherwise she proposes arbitration.

Proposition 13 is now immediate form Claims 3 and 4.

\section{References}

Admati, A. R and M. Perry (1991). "Joint Projects without Commitment". Review of Economic Studies, 54, 259-276.

Ashenfelter, O. (1987). "Arbitrator Behavior". American Economic Review, AEA Papers and Proceedings, 77, 343-346.

Ashenfelter, O. and D. E. Bloom (1984). "Models of Arbitrator Behavior: theory and Evidence". American Economic Review, 74, 111-124.

Bloom, D. E. (1986). "Empirical Models of Arbitrator Behavior under Conventional Arbitration". The Review of Economics and Statistics, 64, $578-585$.

Compte O. and P. Jehiel (1995). "On the Role of Arbitration in Negotiations ". mimeo.

Compte O. and P. Jehiel (2002). "Gradualism in Bargaining and Contribution Games ". Review of Economic Studies forthcoming. 
Farber, H. S and M. H. Bazerman (1986). "The general basis of arbitrator behavior: an empirical analysis of Conventional and Final-Offer Arbitration". Econometrica, 54, 819-844.

Gibbons, R. (1988). "Learning in Equilibrium Models of Arbitration". American Economic Review, 78, 896-912.

Kalai, E. and R. Rosenthal (1979) "Arbitration of Two-party Disputes under Ignorance" International Journal of Game Theory, 7, 65-72.

Manzini, P. and M. Mariotti.(1999). "Joint Outside Options in Bilateral Negotiations: Theory and Applications", mimeo.

Manzini, P. and M. Mariotti.(2001). "Perfect Equilibria in a Model of Bargaining with Arbitration". Games and Economic Behavior, 37, 170-195.

Ponsatí, C. and J. Sakovics (1998). "Rubinstein Bargaining with TwoSided Outside Options". Economic Theory, 11, 667-72.

Shaked, A. (1994). "Opting out: Bazaars versus "hi tech" markets". Investigaciones Económicas, 19, 421-432.

Shaked, A. and J. Sutton (1984). "Involuntary Unemployment as a Perfect Equilibrium in a Bargaining Model". Econometrica, 52, 1351-1364. 